\title{
Hypoxia and Hypercapnia: Sensory and Effector Mechanisms
}

\author{
Kulchitsky Vladimir ${ }^{1 *}$, Zamaro Alexandra ${ }^{1}$ and Koulchitsky Stanislav ${ }^{2}$ \\ ${ }^{1}$ Institute of Physiology, National Academy of Sciences, Minsk, Belarus, Europe \\ ${ }^{2}$ Liege University, Liege, Belgium, Europe
}

Received: 畊 September 03, 2018; Published: 阱 September 05, 2018

*Corresponding author: Kulchitsky Vladimir, Institute of Physiology, National Academy of Sciences, Minsk, Belarus, Europe

Keywords: Central Chemoreceptors; Peripheral Chemoreceptors; Regulation of Respiration

Abbreviations: ATP: Adenosine Triphosphate; $\mathrm{CO}_{2}$ : Carbon Dioxide; $\mathrm{H}^{+}$: Hydrogen Ions; $\mathrm{O}_{2}$ : Oxygen

\section{Introduction}

Human life is determined by plenty of factors, and normal oxygen environment is one of the most important. Mammals and human have obtained specific receptors during the evolution. These receptors are located in blood vessels and tissues and react on hypoxic stimulus [1-3]. Arterial system has the highest density of peripheral chemoreceptors which react on oxygen $\left(\mathrm{O}_{2}\right)$ content change in the internal milieu [1]. Chemoreceptors located in carotid body in the area of carotid arteries bifurcation are the most important [2-5]. Significant part of cardiac output heads via carotid and vertebral arteries to brain, and strategically vital localization of those receptors in carotid body allows them to determine $\mathrm{O}_{2}$ content in blood almost instantly during each output. Some scientist's associate metabolism of mitochondria in carotid body cells with cellular depolarization in order to explain how is signaling to brain initiates [3]. Therefore, brain instantly receives information about blood saturation with $\mathrm{O}_{2}$ by carotid sinus nerve from chemoreceptor cells in carotid body. And this information outruns the one about $\mathrm{O}_{2}$ content which reaches brain via blood vessels. This first information is important for making a quick decision about necessity of corrections of respiratory and vasomotor functions to maintain optimal respiratory homeostasis. When incoming by carotid sinus nerve data does not correspond to genetically and evolutionally stated optimal $\mathrm{O}_{2}$ saturation in arterial blood, the mechanisms aimed at activation of lung ventilation and cardiovascular activity are triggered in brain stem. Moreover, suprabulbar mechanisms form specific locomotors behavior and emotional reactions in hypoxia [6].

\section{Central and Peripheral Mechanisms of Breathing Regulation}

Which mechanism helps living organism make timely decisions in situations when discrepancy between amount of arriving $\mathrm{O}_{2}$ and energy needs in brain's nerve tissue develops? The mechanism of precise control of carbon dioxide $\left(\mathrm{CO}_{2}\right)$ and hydrogen ions $\left(\mathrm{H}^{+}\right)$- but not $\mathrm{O}_{2}$ - in brain tissue has been evolutionally chosen. Such receptor mechanisms (central chemoreceptors) were formed close to neural networks of respiratory center - at caudal brain stem [7-9].

Actually, ideal system for quick decision making by neural network of respiratory center has been evolutionally formed in brain tissue. This system analyzes "input" signals from peripheral chemoreceptors of carotid body $\left(\mathrm{O}_{2}\right.$ level $)$ and "output" ones depending on metabolic rate - from central chemoreceptors $\left(\mathrm{CO}_{2}\right.$, and $\mathrm{H}^{+}$level) [7-9]. The system is very efficient and graceful. Respiratory center receives exact information about $\mathrm{O}_{2}$ content right after output of blood portion from heart. Central chemoreceptors constantly inform respiratory center about the rate of metabolic processes in brain monitoring content of $\mathrm{H}^{+}$and $\mathrm{CO}_{2}$ in brain stem tissue. Reconciliation of "input" and "output" information allows respiratory center performing adequate correction of homeostasis control $[4,5,7,8]$.

Figure 1 shows scheme which allows arranging thoughts expressed above. Signal about $\mathrm{O}_{2}$ content in blood arrives from carotid body (1) via carotid sinus nerve to respiratory center (3), and the ones about $\mathrm{CO}_{2}$ content in brain tissue - from central chemoreceptors (2). Neural network of respiratory center analyzes 
this information and guarantees speed and adequacy of decisions to maintain respiratory homeostasis. Information coming from receptors in lung airways (4) by vagus nerve is important for determining the state of lung ventilation. And the integrity of this information is crucial for making decisions about parameters of lung ventilation involving the main inspiratory muscle - diaphragm (5).

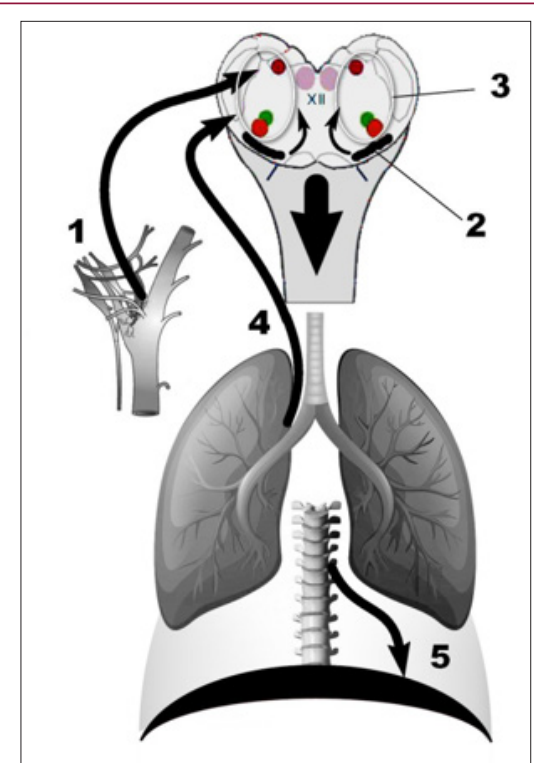

Figure 1: Regulation of lung ventilation (scheme).

1 - carotid body, 2 - medullary (central) chemoreceptors, 3 - respiratory center structures, 4 - vagal afferent nerve terminals, 5 - diaphragm. XII - the nucleus of the hypoglossal nerve. Arrows correspond to directions of signal flow (figure by Dmitry Tokalchik).

\section{The Controversial Hypothesis of Breathing Regulation}

Above presented classic scheme of breathing autoregulation was queried recently $[10,11]$. Scientists dispute about adding one more element to the scheme (Figure 1) [4,5,10-12]. Several authors $[10,11]$ consider namely glial elements (astrocytes) in brain stem the key sensors to hypoxic stimulus $[10,11]$, and not the neuronlike receptor elements responding to $\mathrm{CO}_{2}$ shifts. This point of view $[10,11]$ is confirmed by experimental data on specific reactions of astrocytes in anesthetized rats in simulated hypoxia. The content of signaling molecules - ATP - changes in astrocytes informing respiratory center about hypoxia $[10,11]$. But what is really brought into classic scheme of breathing autoregulation? It is proposed to drive a wedge of additional frigidly responding to respiratory homeostasis shifts mechanism, associated with functional state of astroglia, into effectively functioning system of specific response of peripheral and central chemoreceptors to, respectively, hypoxic and hypercapnic stimuli $[10,11]$. This original, but weakly substantiated point of view is refuted by Specialist in the field of mechanisms of respiratory homeostasis control [4,5]. Reference [10,11] to electrophysiological features of astroglia [13] by followers of new hypothesis [10,11] looks incorrect. Authors [13] presented data on three types of astrocytes, the most of them serving as buffer system of extracellular glutamate and potassium excess and only single glial cells play role in neuronal plasticity. Therefore, it is incorrect to use such interesting data to rationalize sensory functions of astrocytes. It looks $[10,11]$ like the casual theatre visitor speaking for master of ceremonies key role in performance, because there will be no drama without him.

\section{Limitations of the Controversial Hypothesis of Breathing Regulation}

The nature is unable to put into words indignation at irrationality of human actions. But the consequences of adding an additional insensitive element into classic scheme of respiratory homeostasis control [10,11] are obvious for living organism. Significance of signals incoming from vascular interoreceptors [1] is substantiated by the fact (Figure 2).

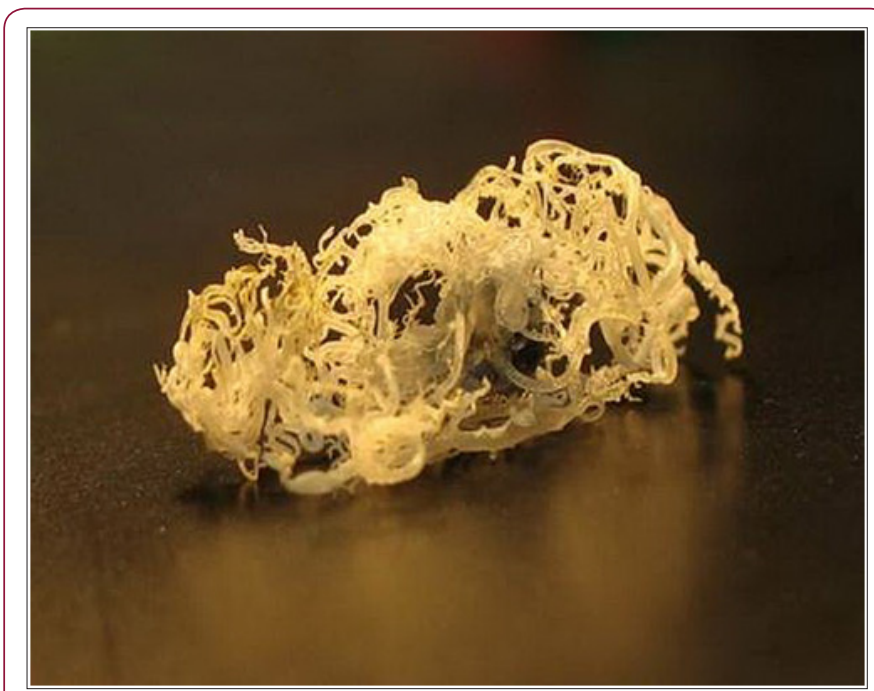

Figure 2: Vascular tree of rat's brain (perfusion of Protacryl-M, cold-setting adhesive, was done by Senior Scientist Margarita Dosina in anesthetized rat via catheter placed into internal carotid artery).

The figure represents dense vascular network of brain. Interoreceptors, including the ones which react on $\mathrm{O}_{2}$ content change [1], are densely distributed in vascular walls. There is little to suggest that nature would require astroglial cells as an alternative. Why? Evolution process is characterized by plenty of patterns, simplicity of complex issues solving and avoiding of excesses being among them. According to classic hypothesis, a kind of balanced "labor differentiation" evolved in mechanism of respiratory homeostasis maintenance. The content of $\mathrm{O}_{2}$ in blood is instantly determined by carotid body receptors in blood flow heading to brain. Astroglial cells wait for the first portion of blood which is now in major vessels after heart contraction. So, astroglial cells appear outsiders in the mechanisms of $\mathrm{O}_{2}$ chemoreception. If only this question would be finished by intellectual discussion. But the facts obtained are necessary for therapy of patients [1416]. Therefore, it is advisable to avoid proof less hypotheses in physiology and medicine [10,11], because ambitiousness of disputants may help forget patient's destiny. 


\section{Conclusion}

Key mechanisms of respiratory homeostasis control have been reviewed from the modern positions. These mechanisms are based on the principles of evolutionary enhancement of feedback of responses from vascular (peripheral) chemoreceptors which react mainly on shifts of oxygen content in blood and medullary (central) ones which keep track on levels of carbon dioxide and hydrogen ions in brain tissue. Concerted activity respiratory center neural network in the process of signal processing from central and peripheral chemoreceptors is the basis for effective control of respiratory homeostasis at slightest shifts of $\mathrm{O}_{2}$ content in blood and $\mathrm{CO}_{2}$ and $\mathrm{H}^{+}$ions concentration in brain tissue.

\section{References}

1. Chernigovsky VN (1976) Tissue receptors. Historical scope. Modern view. Perspectives. Prog Brain Res 43: 3-14.

2. Chang AJ (2017) Acute oxygen sensing by the carotid body: From mitochondria to plasma membrane. J Appl Physiol 123(5): 1335-1343.

3. Holmes AP, Ray CJ, Coney AM, Kumar P (2018) Is Carotid Body Physiological $\mathrm{O}_{2}$ Sensitivity Determined by a Unique Mitochondrial Phenotype? Front Physiol 9: 562.

4. Teppema LJ (2018) CrossTalk opposing view: The hypoxic ventilatory response does not include a central, excitatory hypoxia sensing component. J Physiol doi: 10.1113/JP275708.

5. Teppema LJ (2018) Rebuttal from Luc J. Teppema. J Physiol doi: 10.1113/ JP276281.

6. Kulchitsky VA (2011) Extrasynaptic mechanisms of interneuronal communication: Signal transduction in nervous cells. Res Signpost: 2338.

\section{ISSN: 2574-1241}

DOI: 10.26717/BJSTR.2018.08.001692

Kulchitsky Vladimir. Biomed J Sci \& Tech Res

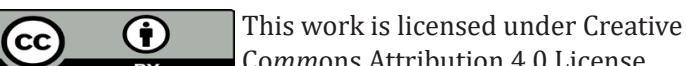

Submission Link: https://biomedres.us/submit-manuscript.php
7. Schläfke ME, Pokorski M, See WR, Prill RK, Loeschcke HH (1975) Chemosensitive neurons on the ventral medullary surface. Bull Physiopathol Respir (Nancy) 11(2): 277-284.

8. Schlaefke ME, Kille JF, Loeschcke HH (1979) Elimination of central chemosensitivity by coagulation of a bilateral area on the ventral medullary surface in awake cats. Pflugers Arch 378(3): 231-241.

9. Nattie E, Li A (2012) Central chemoreceptors: Locations and functions. Compr Physiol 2(1): 221-254.

10. Funk GD, Gourine AV (2018) CrossTalk proposal: A central hypoxia sensor contributes to the excitatory hypoxic ventilatory response. J Physiol doi: 10.1113/JP275707.

11. Funk GD, Gourine AV (2018) Rebuttal from Gregory D. Funk and Alexander V. Gourine. J Physiol doi: 10.1113/JP276282.

12. Koulchitsky SV, Azev OA, Gourine AV, Kulchitsky VA (1994) Capsaicinsensitive area in the ventral surface of the rat medulla. Neurosci Lett 182(2): 129-132.

13. Grass D, Pawlowski PG, Hirrlinger J, Papadopoulos N, Richter DW (2004) Diversity of functional astroglial properties in the respiratory network. J Neurosci 24(6): 1358-1365.

14. Semenik TA, Andrianova TD, Alfer IY, Tsishkevich KS, Kaliadzich ZV, et al. (2014) Analysis of contribution of chemosensitive structures to the development of obstructive sleep apnea. Fiziol J 60(3): 50.

15. Kulchitsky V, Semenik T, Kaliadzich Z, Andrianova T, Tsishkevich K (2014) The analysis of chemosensitive structures contribution to obstructive sleep apnea development. Clin Neurophysiol 125 (1): S330-S331.

16. Kaliadzich Z, Semenik T, Riazechkin A, Furmanchuk D, Andrianova T, et al. (2014) Chemoreceptor control of gas homeostasis in patients with obstructive sleep apnea. Act Nerv Super Rediviva 56(3-4): 73-78.

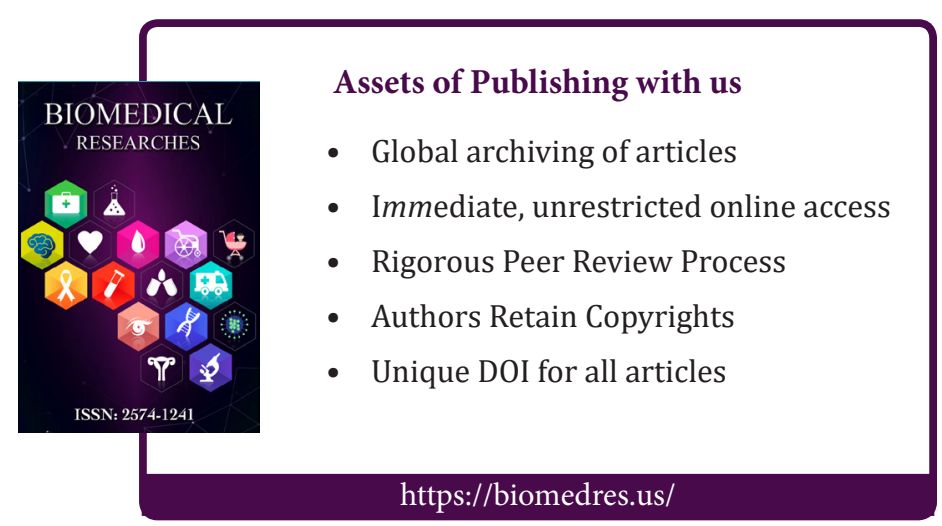

